\title{
An Empirical Analysis of the Positive Impact of Ethics Teaching on
}

\section{Accountancy Students}

\author{
Dr. Conor O’Leary \\ Senior Lecturer, \\ School of Accountancy, \\ Queensland University of Technology, \\ Brisbane, Australia.
}

Dr. Conor O'Leary (corresponding author)

School of Accountancy

Queensland University of Technology

Brisbane, Australia.

Phone: +61 731381019

Fax: +61 738641812

Postal: GPO Box 2434, Brisbane, Qld 4001. Australia.

Email: c.oleary@qut.edu.au 


\title{
An Empirical Analysis of the Positive Impact of Ethics Teaching on Accountancy Students
}

\begin{abstract}
Recent releases from the International Federation of Accountants (IFAC) highlight the importance of ethics education. Academic institutions employ varying methods and place varying levels of emphasis on ethics teaching during a business/accounting degree. This paper attempts to evaluate whether teaching ethics to final year accountancy students is beneficial. At the commencement of a semester, one class of 155 students were given five ethical scenarios on which to make an ethical decision. All students were then subject to three different methods of ethical instruction. Several weeks later the class were again given the original five ethical scenarios and asked to re-complete. In all five instances the mean responses were more ethical after the instruction methodologies. The subjects also verified that the combined effect of the methodologies had impacted positively on hypothetical ethical decision making. Hence it appears ethics education is beneficial, the challenge is to find the optimal method(s).
\end{abstract}

Keywords: Teaching, Ethics, accountancy students, methodology, empirical tresting. 


\section{An Empirical Analysis of the Positive Impact of Ethics Teaching on Accountancy}

\section{Students}

\section{Introduction}

There has been disagreement in the literature on both the need for ethics education for accountancy students (Piper et al, 1993; McDonald and Donleavy, 1995; Peppas and Diskin, 2001), and the nature of that education. The importance of the first issues has been brought back into focus due to the many corporate scandals reported in recent times (such as Enron and WorldCom in the United States and HIH in Australia). Some of these scandals have involved egregious ethical failures by accounting firms or individual accountants. The response of the accounting professional bodies is typified by recent releases from the International Federation of Accountants (IFAC, 2006) such as IFAC's International Accounting Education Standards Board's (IAESB) new guidance "International Education Practice Statement (IEPS)". This statement focuses on the implementation of good practice and maintenance of professional values, ethics and attitudes in accordance with International Education Standard (IES) 4 .

The need for ethical education is also dependent upon whether or not such teaching is proven to be effective. Thomas (2004) addresses the issue of whether ethical training can be effective and highlights studies such as Armstrong (1993) and Piper et al. (1993) which offer positive arguments in favour of this proposition. This paper hopes to extend research in this area and ascertain what impact formal teaching has on ethical attitudes. 
The issue of the nature of ethics instruction revolves around whether ethics should be taught as a stand-alone topic (Hanson, 1987; Loeb, 1998) or whether it should be integrated throughout the entire accountancy course (Thomas, 2004; Swanson, 2005; Bodkin and Stevenson, 2007). Another suggestion has been a combined approach of a general ethics course, followed by the integration approach via case studies, and concluding with a capstone course in ethics and professionalism (Langenderfer and Rockness, 1989; Armstrong, 1993; Thomas, 2004).

But what is a positive ethical attitude for an accountant and can it be taught to accounting students? In psychological terms, possessing an ethical mind-set involves consistent practice of ethical principles (Gardner, 2007). Whilst an ethical orientation is first cultivated in the home, and is later influenced by peers and the standards of the surrounding community, the improper or even criminal behaviour of others can undermine it in the business context. The notion of 'consistent practice' suggests that, whilst it may be true that students come to university with certain patterns of behaviour ingrained (Alam, 1999; Adams et al, 1999), it is possible to train them to work ethically, or more ethically if their ethical orientation is partially developed, and to resist the influence of others behaving unethically when at work (Hiltebeitel and Jones, 1991).

However, not all research supports the notion of ethical and moral growth over time through education. Some researchers have found that students with high positive scores on ethical tests could also behave unethically, even though they had been exposed to ethics education and have attained higher-stage development in ethical assessment models (Ponemon, 1993; Bay and Greenberg, 2001; Thomas, 2004). 
The purpose of this paper therefore is to investigate the impact of instruction in ethics on accounting students, and to query whether ethics instruction can prove effective in building ethical awareness in students. Does the teaching of ethics have any positive effect on students' moral and ethical development? The remainder of the paper is structured as follows. First, a literature review is presented which surveys prior research in the area. A research proposition is then developed and the research design outlined. Subsequent sections analyse the findings of the study conducted, discuss the results, recognise limitations in the work, and identify areas for future research.

\section{Literature review}

Kohlberg (1969, 1981) proposed a model of ethical training which suggested that ethical and moral growth could be developed over time through education. His three stage model of pre-conventional, conventional and post-conventional moral development underpins most of the ethics teaching which takes place in tertiary classrooms today. The aim of this training is to promote the highest level of ethical thinking, which in turn should lead to consistently ethical behaviour. This model was further refined by Rest $(1986,1990)$ in his Defining Issues Test (DIT). In contrast, other researchers wish to promote 'virtue' ethics as superior to the mechanistic style of the Kohlberg stage model (Mintz, 1995; Stewart, 1997). Attempts have also been made to integrate the two approaches (Thorne, 1998; Armstrong et al, 2003).

Irrespective of which type of education model is used, practical studies evaluating actual accountancy students' ethical attitudes have on occasion revealed disappointing results. This again supports the perceived need for formal instruction in the area. In a 
study by Cree and Baring (1991) a significant proportion of students was found to be open to an insider-trading proposition. Haswell and Jubb (1995) noted almost 50\% of male and $25 \%$ of female students indicated a willingness to accept a bribe if there was no risk of being caught. More recent studies have also yielded unsettling results. O'Leary and Cotter (2000) found that 58\% of Irish students and 23\% of Australian students were willing to participate in fraud. Similar findings were attained by O’Leary and Radich (2001), whereby $26 \%$ of Australian students were willing to defraud the taxation office and $21 \%$ to defraud shareholders. Only the risk of being caught appeared to reduce unethical tendencies, not the nature of the act.

As regards the nature of ethical instruction, proponents of the single subject approach see the discrete ethics subject as providing a clearer focus for ethics education, as well as the basis for a more profound rationale for the training in students' minds, and for the emphasis on a framework for students to use in subsequent practice when faced with an ethical issue (Leung and Cooper, 1994). This has the appearance of a mechanistic approach to ethics education, and may suggest that ethics issues are limited to one area in practice (Low et al, 2006; Boyce, 2006).

Most researchers favour integration as the superior mode of introducing students to ethical training, on the basis that it provides for a wider variety of ethical experiences in the course of the training, which more properly reflects the variety of ethical situations an accountant might meet in practice (Bampton and Cowton, 2002). In addition, Alam (1999) found that the majority of accounting teachers surveyed favoured the integration approach, or the combined approach of an ethics subject and integration through the rest of the course. 
Hiltebeitel and Jones (1991) suggested that the single course model was insufficient, but reported that there had been little integration of ethics training into accounting programs at that time. Bampton and Cowton (2002) discovered that few classroom teachers actually covered ethics issues explicitly or at any great length, the longest coverage reported being five hours in a typical accounting subject. Similarly, a survey of US colleges and universities found that around 7.5\% of class time was spent on ethics in a typical accountancy semester (Madison and Schmidt, 2006). Whether this amount of time is appropriate is a matter for debate. However, it suggests that the lack of integration reported by Hiltebeitel and Jones (1991) does not appear to have changed greatly in the intervening years, because difficulties have been identified in using the integration methodology in accounting classroom practice. These include lack of training for teachers, lack of time or materials, lack of motivation, a view that ethics is not really part of an accountant's rigorous practical training, and the prevailing culture of business schools (Langenderfer and Rockness, 1989; Hiltebeitel and Jones, 1991; Daly, 1997; Gunz and McCutcheon, 1998; Bampton and Cowton, 2002; Adkins and Radtke, 2004; Low et al, 2006; Boyce, 2006; Beggs and Dean, 2007). This has resulted in a piecemeal and ad hoc approach to ethics education. Moreover, the effects of these ethics interventions were not found to be long-lasting (Hiltebeitel and Jones, 1991; McNair and Milam, 1993; Richards, 1999).

Why should ethics be so difficult to teach effectively in accounting and why does even 'best practice' ethics teaching not persist in students' minds when they progress to the profession? Daly (1997) offers two reasons. First, he argues that ethics education is too issue-driven. Ethics only becomes newsworthy every time there is a flurry of business failures and accounting scandals, and universities are then required 
to respond to that in their accounting courses by either professional bodies or funding sources. Hence, approaches to teaching ethics are fragmentary or poorly planned with inadequate materials and ill-prepared teachers.

Second, teaching methods are reactionary. Ethics teaching methodologies are often by case studies, which merely assist students to recognise ethical dilemmas in a shortterm and ad hoc way, and respond to them as instructed. This rules-based approach has been criticised as inadequate in developing ethical judgement (Waddock, 2005; Michael, 2006). This study utilises case studies but they are presented in three ways to the participants, by way of formal lecture, an interactive computer tool and group discussion. It is hoped then to evaluate whether these methods individually, or in combination have an impact. Hopefully this then will add to the extant literature in the area.

It has been suggested that if ethics education in accounting is possible, there must be agreement about the broader goals of ethics education in accounting, as well as relevance to students, and other stakeholders, a properly conducted debriefing stage in the training, and well-designed assessment. (Geary and Sims, 1994; Brinkmann and Sims, 2001). In the US, the National Association of State Boards of Accountancy (NASBA) and the American Accounting Association (AAA) conducted a survey of ethics education in tertiary business schools in 2004 and found that $46 \%$ of colleges offered a separate course in ethics and of those colleges, $68 \%$ of their business schools allowed access to that course. Only $18 \%$ of the business schools offered the course in their accounting departments, however (Mastracchio, 2005). 
A survey of accounting academics conducted by Beggs and Dean (2007) found that accounting faculty were relatively unmoved by recent corporate scandals, attributing them to management failure rather than accounting failures. In this context, the latest ‘ethics crisis’ was not something new and could not be addressed by ethics education. This view seems to ignore the fact that these scandals were mostly failures of audit procedures and standards (Bean and Bernardi, 2007). Beggs and Dean suggest various ways to address this attitude, including more positive support for ethics teaching, more interaction with stakeholders in business, and a rethinking of business school culture. This survey showed a more negative outcome than that conducted by Adkins and Radtke (2004) which pointed to a more self-satisfied viewpoint from faculty members, and a more positive support for ethics education by students, though this may have been a reflection of the survey being conducted prior to the full fall-out from the WorldCom, Tyco, Adelphia and Martha Stewart scandals.

As to goals of ethics education in accounting, Loeb (1988) offered seven possible goals which have been widely discussed. Loeb (1991) has also linked these goals with assessment, but can suggest nothing more than:

reliance probably should be placed on the more familiar evaluation techniques e.g. test, papers, student evaluations of faculty... However, as accounting faculty members become more comfortable in ...the teaching of ethics, more innovative evaluation techniques might be considered.' (1991, p.82). 
Boyce (2006) and Low et al (2006) discuss the goals of ethics education in the context of a critique of business school culture. Ethics may be able to be taught, but in what context and can the outcomes be long lasting?

\section{Hypothesis and research design}

The above review is just a synopsis of some of the extant literature in the area. It would appear, as summarised by Bampton and Maclagan (2005), that what is required is research which shows that goals, content (rules and stages or moral philosophy), methodology (stand-alone courses or integrated courses), pedagogy (experiential or non-experiential), and long term impact can all be linked. This paper focuses on the first topic, namely the goal of teaching ethics (to improve ethical attitudes) and whether instruction can be proved effective. The paper therefore attempts to ascertain whether ethics instruction can, in the first instance, impact positively on future accountants.

Based on the above analyses and findings of past research, it can be observed differing views surround even the core question of whether ethics is considered a critical component of accounting education. Even if answered in the affirmative, different views then exist as to the nature of ethical instruction that should be adopted. Results of past surveys of accounting students appear to reflect the lack of consensus on these two issues, in that behaving ethically does not seem vital to students' attitudes to working in the accounting profession. Moreover, the only motivation for students to act ethically appeared to be if the risk of getting caught existed. This tends 
to suggest either the amount of time being devoted to it is inadequate or the methods being used are ineffective.

Based upon the actions of IFAC, as mentioned in the introduction, the accountancy profession appears intent on enhancing ethical instruction for accountancy trainees. This paper therefore sets its research question (RQ) as follows:

RQ: Does teaching ethics to final year accounting students have any impact on their hypothetical ethical decision making?

\section{Research Method}

\section{Sample}

One final year undergraduate accounting class, studying auditing, took part in the experiment. From the enrolled numbers 155 students completed the survey instrument in the first lecture. When the survey instrument was completed again in week six (refer to the Procedures section below) 118 valid responses were received. This is how the final numbers as per Table 1 were arrived at. The median age bracket for these final year students was 19-21 years and 65\% were females and 35\% males.

Week six clashed with some mid-semester assessments in other subjects and so the numbers were down by some $20 \%$ on the first lecture. Almost all students completed the survey instrument in week 1 so there was no issue of non-response bias. However in week 6, as mentioned above, 37 students who had completed the first copy of the survey instrument were not present to complete the follow up stage. As their absence could be explained (by their decision to commit more time to other subjects that 
particular week) there is no reason to consider the non-respondents would have been more or less significantly impacted by the ethics education than those who responded the second time.

\section{Survey Instrument}

For the purpose of collecting data, five ethical vignettes were used as an instrument within the experiment. This instrument allows ethical problems to be placed in a reasonably realistic context and directs the focus on to a particular area of interest. Ethical vignettes provide significant advantages over other research instruments when investigating ethical principles and ethical behaviour (Cavanaugh and Fritzche, 1985). Within the accounting field, numerous studies in accounting ethics have used ethical vignettes (Douglas et al., 2001; Patterson, 2001). The ethical vignettes in this study similarly describe possible ethical dilemmas that may arise in an accountant's working environment. More recent studies, such as Fleischman et al. (2007) have utilised more detailed scenarios in ethical evaluations, which provide more information and business context. Whereas these scenarios have the advantage of being more thorough that vignettes, they were deemed too complex and time consuming for the current participants to absorb, within the confines of the current experimental environment.

The five ethical vignettes are all accounting-related vignettes and have been specifically developed for this study. (Refer to Appendix 1 for a copy of the first vignette from the survey instrument). All the vignettes portray a scenario in which a recently graduated accountant has spent six months in his/her first job and is faced with an ethical dilemma. The following describes the five vignettes: 
Vignette 1 - describes a situation where an assistant accountant working in a chemical company is offered a once-off payment by the Chief Accountant to keep silent regarding improper accounting practices.

Vignette 2 - depicts a scenario where an accounting clerk working in a confectionary company witnesses a respected senior colleague stealing a box of chocolates.

Vignette 3 - describes a situation in which the assistant accountant, is being presented with the opportunity to falsify his/her resume application for a job.

Vignette 4 - illustrates a scenario in which a trainee accountant is being pressured to inflate travel expenses for reimbursement.

Vignette 5 - depicts a situation whereby a trainee accountant is being pressured to make necessary adjustments to a client's accounts, in order for a bank loan to be approved.

At the end of each of the five scenarios, students were asked to select one response from five alternatives (Appendix 1). Although the five responses in each of the scenarios are tailored to the particular ethical dilemma, the first response in all scenarios always represented the response to act highly unethically; the second response to act unethically; the third response to act neutral; the fourth response to act ethically; and the fifth response to act highly ethically. The highly ethical response involved becoming a whistleblower on the perpetrator(s) of the unethical behaviour.

\section{Procedures}

The survey instruments (SIs) were distributed as follows. At the first lecture in a final year Bachelor of Business subject (Auditing) a copy of the SI was distributed to each 
individual and they were advised to complete them individually and hand them up during the lecture break. They were told it did not form part of the assessment procedures for the subject, that there were no right or wrong answers and they were to answer according to how they genuinely felt at the time. Completion of the survey instrument took approximately 10 minutes. This distribution yielded the 155 pre instruction responses.

The first lecture consisted of a one hour introduction to auditing and then a one hour lecture on ethics in auditing. This included an introduction to the Code of Ethical Conduct of the professional accounting bodies in Australia; a discussion of ethical theory (including fundamental accounting ethics concepts such as integrity, objectivity, competence, confidentiality and professional behaviour); and examples of the results of unethical accounting practices (involving discussions on the Enron case in the United States and the $H I H$ case in Australia). The students were set readings from their text (Arens et al. 2006) and questions on ethics to be answered in the following week's tutorial. This lecture/tutorial combination comprised ethics instruction method number 1.

In the second week of the course the students were given a one hour lecture on how to solve an ethical dilemma using a six-step model explained in their textbook. Their tutorial work for the following week was to work through an interactive computer based education (CBE) ethics training case study, formerly used as an instruction instrument by the Institute of Chartered Accountants in Australia as part of their training programme. They had a week to work through the CBE tool and present a one page memo as to their recommended solution to the ethical problem posed 
therein. The CBE tool involves providing the user with the details of an audit partner receiving an "opinion shopping” request. The user then has to work through the following six step model to solve the dilemma:

1. Obtain the relevant facts

2. Identify the ethical issues from the facts

3. Determine all stakeholders and how they are affected

4. Identify the alternatives available

5. Identify the consequences of each alternative

6. Decide the appropriate action.

Each screen pops up in turn with a list of factors to be considered at each stage. The user is therefore forced to work through the full ethical decision-making model before being directed to the appropriate action as stated in the accountants' code of professional conduct. The participants did this as individuals and this comprised ethics instruction method number 2 .

In the third week of the course students were given a group assignment. They were to form groups of 3 students and present a full written assignment (6 pages approximately) answer to two ethical dilemmas, a confidentiality dilemma and an independence issue. They were given two weeks to complete the assignment. This group written assignment comprised ethics instruction method number 3. All formal ethics instruction ceased as part of the Auditing unit at this point. 
A three week "cooling off" period then ensued. Normal audit topics were discussed and studied and no reference was made in classes to any ethical content or implications. The purpose of this was to hopefully clear the students' minds of focussing too intently on the ethical components of anything they were studying.

In week six of the course, after the students had handed up their assignment previously, the students were given the same survey instrument they had received in week 1 . This was a total surprise to them in that they had not been told they would be doing it again, when doing it in week 1 . Again it was stressed to them it did not form part of the assessment procedures for the subject, that there were no right or wrong answers and they were to answer according to how they genuinely felt at the time. This distribution yielded the 118 post instruction responses assessed as per Table 1 . The last page of the SI then asked them to rank the overall impact of all methods, on a nine point scale. The bottom end of the scale represented a response stating the ethical instruction methods had made them inclined to act more unethically than previously, the mid-point (5) represented a response stating the ethical instruction methods had no effect on their ethical attitudes. Finally, the top of the scale represented a response stating the ethical instruction methods had made them inclined to act more ethically.

\section{Results}

Table 1 provides a summary of the mean responses to the five vignettes pre and post the three instruction methods. 


\begin{tabular}{|l|l|r|r|r|r|l|}
\hline \multicolumn{2}{|c|}{ Table 1 - Comparison of Means Pre and Post Ethics Teaching Methods } \\
\hline & & \multicolumn{1}{c|}{$\mathrm{N}$} & \multicolumn{1}{c|}{ Mean } & $\begin{array}{c}\text { Std. } \\
\text { Deviation }\end{array}$ & \multicolumn{1}{c|}{$\mathrm{t}$} & Sig. (2-tailed) \\
\hline $\begin{array}{l}\text { Scenario } \\
1\end{array}$ & Pre & 155 & 3.9290 & 1.201 & -1.644 & $.101 \mathrm{n} / \mathbf{s}$ \\
\hline & Post & 118 & 4.1525 & .983 & -1.689 & $.092 *$ \\
\hline $\begin{array}{l}\text { Scenario } \\
2\end{array}$ & Pre & 154 & 3.6429 & .940 & -.116 & $.908 \mathrm{n} / \mathbf{s}$ \\
\hline & Post & 119 & 3.6555 & .827 & -.118 & $.907 \mathbf{~} / \mathbf{s}$ \\
\hline $\begin{array}{l}\text { Scenario } \\
3\end{array}$ & Pre & 155 & 2.5871 & .888 & -3.292 & $.001 * * * *$ \\
\hline & Post & 118 & 2.9237 & .764 & -3.359 & $.001 * * * *$ \\
\hline $\begin{array}{l}\text { Scenario } \\
4\end{array}$ & Pre & 154 & 3.1558 & .991 & -2.265 & $.024 * *$ \\
\hline & Post & 118 & 3.4407 & 1.074 & -2.241 & $.026 * *$ \\
\hline $\begin{array}{l}\text { Scenario } \\
5\end{array}$ & Pre & 155 & 3.4387 & 1.248 & -3.014 & $.003 * * *$ \\
\hline & Post & 117 & 3.8889 & 1.180 & -3.038 & $.003 * * *$ \\
\hline
\end{tabular}

The ideal way to analyse this data would be to identify each student individually and do a matched pair comparison of their pre and post-instruction responses. However this would entail asking participants to identify themselves when completing the SI both times. Confidentiality constraints precluded this. Previous experiments which have requested subject identification usually result in significantly smaller sample sizes. Hence participants were assured of confidentiality and the results analysed on a collective group basis. Two-tailed tests were performed rather that one-tailed for two reasons. First, as mentioned in the literature review, not all research has concluded that teaching ethics always has a positive impact. Some researchers as noted earlier still query the benefits of ethics education. Second, the possibility of some participants becoming frustrated by the emphasis on ethics in this subject and so intentionally scoring lower the second time, had to be considered. Hence anticipating the direction of change was not considered prudent. 
In all five instances the mean score was higher for each scenario after the instruction methods. Four responses are statistically significantly different. The fifth produced means too close to imply directionality. This would tend to suggest that after considering the importance of ethics in accounting, the students considered a more ethical response to an ethical vignette than had they not been exposed to the importance of the topic.

Correlation tests were performed to evaluate consensus levels across the two groups, the 155 who performed the first SI completion and the 118 who performed the second completion. Appendix 2 summarises the results of these tests. In both instances 16 of a possible 20 correlations revealed significant levels. These results add support to the notions that the vignettes were perceived as realistic, individual responses within the groups were not haphazard, and a certain degree of homogeneity existed within the cohort.

When asked about the effectiveness or otherwise of the three instructional methods, participants rated the combined effect of all three as effective. Table 2 lists the results of this test. The mid-point of the nine point scale (5) was set up as a dummy response indicating zero impact on attitudes. The respondents then rated the combined overall effect as significantly greater than the mid-point. As mentioned above, even if there were disillusioned students who intentionally scored negatively, they did not appear to be a significant proportion. Hence it would appear as if the RQ can be answered in the affirmative. 
Table 2 - Accountancy Students Assessment of Effectiveness of Ethics Teaching

\begin{tabular}{|l|c|c|r|r|r|}
\hline Method & $\mathrm{N}$ & Mean & $\begin{array}{c}\text { Std. } \\
\text { Deviation }\end{array}$ & $\mathrm{t}$ & Sig. (2-tailed) \\
\hline $\begin{array}{l}\text { (Dummy Variable }- \\
\begin{array}{l}\text { zero effect) } \\
\text { Overall combined } \\
\text { effect }\end{array}\end{array}$ & 119 & 5.0000 & .000 & & \\
\hline **** = significant at .001 & 118 & 6.7119 & 1.125 & 64.78 & $.000 * * * *$ \\
\hline
\end{tabular}

$* * * *$ = significant at .001

\section{Discussion}

Considering the RQ it would appear as if there is indeed a place for ethics education in accountancy courses. Inclusion of ethical components may not be simply altruistic. They appear to have had a positive impact on the students in this study. Every attempt was made to protect the validity of the study, subject to the limitations noted below. The answers to the survey instrument were not part of the assessment procedures for the unit. It was continually stressed to students their responses were to be what they considered they would do, not what they considered should be done. There was no benefit of any kind for a student to give any answer other than the one they considered relevant. A significant time period was allowed to lapse between when the students were being instructed in ethics and when they completed the SI for the second time.

The researchers had anticipated the ethical instruction methods would not have had any impact on ethical attitudes. It was considered final year accounting students, most of whom have had significant "real world" experience with part time work etc. by the time they get to their final year, would have their ethical values thoroughly formed. As earlier studies - some referred to in the literature review - have established, ethical attitudes are significantly affected by individual factors (such as demographic, 
cultural, religious and psychological) and situational factors (such as organisational culture). Most of these influences impact significantly on individuals well before they reach the final year of their university degree.

It was anticipated the final year accounting students' ethical attitudes would have been strongly developed and a few weeks of instruction would be unlikely to impact them to a significant degree. The results tended to suggest otherwise however. Ethical behaviour in an accounting context was positively impacted upon in all five scenarios, four of them significantly so. This would tend to suggest there is benefit in including ethics teaching and indeed emphasising its importance in accountancy courses.

\section{Summary and Conclusion}

One of the greatest challenges facing the accounting profession today is maintaining exemplary ethical standards. It follows therefore that one of the greatest challenges for accounting academics is how to get the ethical message across to accountancy students, the practitioners of tomorrow. This study examines whether or not ethical instruction, employing a range of techniques, is effective within an accountancy course. Results would tend to suggest, ethical instruction can indeed impact positively on accountancy students' ethical attitudes. A combination of teaching techniques yielded significantly positive results in the main. Additional research in this area (i.e. are some techniques more effective than others) would therefore appear justified and is mentioned below. 
It must be noted that this improvement in ethical attitudes has only been tested in the short term. As some earlier studies (LaGrone et al. (1996) and others noted in the literature review) discovered, some former students' positive ethical attitudes appeared to erode a little over time. Testing for this was considered beyond the scope of the current study.

\section{Limitations}

There are three main limitations to this research study. First, the relatively small sample size may not be considered representative of the overall population that is the accountancy student population, although there are no reasons to believe the students who participated from this university are any different from students from any other universities. However, the generalisability of the results to the final year accountancy students of other universities is unclear.

Second, in terms of the responses to the ethical vignettes, whether the responses are true reflections of what the participants would actually do in a real situation is a factor which will remain unknown. This is a limitation applicable to most studies of this ilk. Factors such as socially desirable response (SDR) bias potentially could result in students offering a more ethical response the second time, just to prove they had learned something. Indeed, the final question, summarised at Table 2 hints at what was being tested. However, it should be noted how it was stressed that answers were to be what participants thought they would do, not what should be done. Also, the question evaluating effectiveness of teaching methods was asked after they had responded to the scenarios, thus supporting the study's validity. Whereas there are no 
reasons to believe that students would react differently to the ethical vignettes than to a real life situation, the findings of this research study must however be read in light of these limitations.

Third, as discussed in the Survey Instrument section, the answer to each vignette offered a five option range of solutions, from most unethical to most ethical, always in the same order. The possibility of the respondents falling into a "pattern effect" must be therefore be considered, even though there is no specific reason to consider the students did not assess each case on its merits and respond accordingly.

\section{Future Research}

Where this paper leads academic instructors is the most important outcome of this research. Results tend to suggest teaching ethics can be effective but which methods are effective? Indeed a combination of methods may achieve more than any one individual method, no matter how effective that individual method appears. It would appear beneficial therefore to continue research into this area. Specifically, future research could focus on: better ways of measuring ethical attitudes and changes therein; better methods of comparing the various methods and evaluating differences; and even developing new methods of teaching ethics.

Acknowledgements: The authors would like to express their gratitude to the Institute of Chartered Accountants in Australia for a grant, which made this research possible. 


\section{$\underline{\text { Appendix } 1 \text { - Example of Ethical Vignette }}{ }^{1}$ (Extracted from Survey Instrument $^{2}$ )}

\section{ETHICAL SCENARIO \# 1}

1. You have completed your business degree and have spent six months in your first job, as assistant accountant in a chemical company involved in various research and development projects. Projects that have high probabilities of earning sufficient future revenue to cover costs are capitalised. You find out that one particular research and development project, already capitalised, has serious doubts regarding its ability to generate sufficient future revenue. You confront your superior, the chief accountant, who reluctantly admits to this fact. You soon learn the chief accountant's bonus is performance-related based on the company’s annual profit, so you become suspicious of his motives for not writing off this and other doubtful projects. The chief accountant becomes concerned this matter troubles you and offers you an annual payment of $\$ 10,000$ - 25\% of your annual salary - for your silence.

Please circle one option:

Would you:

(1) Accept the offer and keep silent?

(2) Accept the offer for one year, but insist it finish then?

(3) Decline the offer and tell no one?

(4) Decline the offer and encourage your boss to confess to the directors (but inform him you won't pursue the matter if he doesn't)?

(5) Decline the offer and report to the directors of the company?

\footnotetext{
${ }^{1}$ As the survey instrument incorporated new vignettes developed for this study (p.12) it was pilot tested on 2 accountancy lecturers and 3 PhD students. All expressed satisfaction as to its relevance and only minor grammatical adjustments were made.

${ }^{2}$ A full copy of the survey instrument is available from authors on request.
} 


\section{Appendix 2-Statistical Analysis. Correlation of Participants' Responses}

First Completion of SI: 16 of 20 significant

\begin{tabular}{|c|c|c|c|c|c|c|}
\hline & & Scenario1 & Scenario2 & Scenario3 & Scenario4 & Scenario5 \\
\hline Scenario1 & $\begin{array}{l}\text { Pearson } \\
\text { Correlation }\end{array}$ & 1 & $.189(*)$ & $.191(*)$ & $.444(* *)$ & $.315(* *)$ \\
\hline & Sig. (2-tailed) & & .019 & .017 & .000 & .000 \\
\hline & $\mathrm{N}$ & 155 & 154 & 155 & 154 & 155 \\
\hline Scenario2 & $\begin{array}{l}\text { Pearson } \\
\text { Correlation }\end{array}$ & $.189\left(^{*}\right)$ & 1 & $.196\left(^{*}\right)$ & $.306\left(^{* *}\right)$ & .070 \\
\hline & Sig. (2-tailed) & .019 & & .015 & .000 & .388 \\
\hline & $\mathrm{N}$ & 154 & 154 & 154 & 154 & 154 \\
\hline Scenario3 & $\begin{array}{l}\text { Pearson } \\
\text { Correlation }\end{array}$ & $.191\left(^{*}\right)$ & $.196\left(^{*}\right)$ & 1 & $.266(* *)$ & .071 \\
\hline & Sig. (2-tailed) & .017 & .015 & & .001 & .382 \\
\hline & $\mathrm{N}$ & 155 & 154 & 155 & 154 & 155 \\
\hline Scenario4 & $\begin{array}{l}\text { Pearson } \\
\text { Correlation }\end{array}$ & $.444(* *)$ & $.306(* *)$ & $.266(* *)$ & 1 & $.348(* *)$ \\
\hline & Sig. (2-tailed) & .000 & .000 & .001 & & .000 \\
\hline & $\mathrm{N}$ & 154 & 154 & 154 & 154 & 154 \\
\hline Scenario5 & $\begin{array}{l}\text { Pearson } \\
\text { Correlation }\end{array}$ & $.315(* *)$ & .070 & .071 & $.348(* *)$ & 1 \\
\hline & Sig. (2-tailed) & .000 & .388 & .382 & .000 & \\
\hline & $\mathrm{N}$ & 155 & 154 & 155 & 154 & 155 \\
\hline
\end{tabular}

Correlation is significant: $* *$ at the 0.01 level (2-tailed), $*$ at the 0.05 level (2-tailed)

Second Completion of SI: 16 of 20 significant

\begin{tabular}{|c|c|c|c|c|c|c|}
\hline & & Scenario1 & Scenario2 & Scenario3 & Scenario4 & Scenario5 \\
\hline \multirow[t]{3}{*}{ Scenario1 } & $\begin{array}{l}\text { Pearson } \\
\text { Correlation }\end{array}$ & 1 & $.337(* *)$ & .098 & $.366(* *)$ & $.395(* *)$ \\
\hline & Sig. (2-tailed) & & .000 & .294 & .000 & .000 \\
\hline & $\mathrm{N}$ & 118 & 118 & 117 & 117 & 116 \\
\hline \multirow[t]{3}{*}{ Scenario2 } & $\begin{array}{l}\text { Pearson } \\
\text { Correlation }\end{array}$ & $.337(* *)$ & 1 & $.187\left(^{*}\right)$ & $.403(* *)$ & $.276(* *)$ \\
\hline & Sig. (2-tailed) & .000 & & .043 & .000 & .003 \\
\hline & $\mathrm{N}$ & 118 & 119 & 118 & 118 & 117 \\
\hline \multirow[t]{3}{*}{ Scenario3 } & $\begin{array}{l}\text { Pearson } \\
\text { Correlation }\end{array}$ & .098 & $.187(*)$ & 1 & $.343(* *)$ & .057 \\
\hline & Sig. (2-tailed) & .294 & .043 & & .000 & .541 \\
\hline & $\mathrm{N}$ & 117 & 118 & 118 & 118 & 117 \\
\hline \multirow[t]{3}{*}{ Scenario4 } & $\begin{array}{l}\text { Pearson } \\
\text { Correlation }\end{array}$ & $.366(* *)$ & $.403(* *)$ & $.343(* *)$ & 1 & $.418(* *)$ \\
\hline & Sig. (2-tailed) & .000 & .000 & .000 & & .000 \\
\hline & $\mathrm{N}$ & 117 & 118 & 118 & 118 & 117 \\
\hline \multirow[t]{3}{*}{ Scenario5 } & $\begin{array}{l}\text { Pearson } \\
\text { Correlation }\end{array}$ & $.395(* *)$ & $.276(* *)$ & .057 & $.418(* *)$ & 1 \\
\hline & Sig. (2-tailed) & .000 & .003 & .541 & .000 & \\
\hline & $\mathrm{N}$ & 116 & 117 & 117 & 117 & 117 \\
\hline
\end{tabular}

Correlation is significant: ${ }^{* *}$ at the 0.01 level (2-tailed), ${ }^{*}$ at the 0.05 level (2-tailed). 


\section{REFERENCES}

Adams, J.S., A. Tashchian and T.H. Shore: 1999, 'Frequency, Recall and Usefulness of Undergraduate Ethics Education’ Teaching Business Ethics 3(3), 241-253.

Adkins, N., and R.R. Radtke: 2004, 'Students’ and Faculty Members’ Perceptions of the Importance of Business Ethics and Accounting Ethics Education: Is There an Expectations Gap?’ Journal of Business Ethics 51, 279-300.

Alam, K.F.: 1999, 'Ethics and Accounting Education' Teaching Business Ethics 2, 261-272.

Arens, A., Best, P., Shailer, G, Fiedler, B. Elder R. and Beasley M. (2006), Auditing and Assurance Services in Australia (6 $6^{\text {th }}$ edn), Pearson Education, Australia.

Armstrong, M B.: 1993, 'Ethics and Professionalism in Accounting Education: A Sample Course’ Journal of Accounting Education 11, 77-92.

Bampton, R., and C.J.Cowton: 2002, 'The teaching of ethics in management accounting: progress and prospects’ Business Ethics: A European Review 11(1), 5261.

Bampton, R., and P. Maclagan: 2005, 'Why teach ethics to accounting students? A response to the sceptics’ Business Ethics: A European Review 14(3), 290-300. 
Bean, D.F., and R.A. Bernardi: 2007, 'Accounting Ethics Courses: Do They Work?’ The CPA Journal, January, 64-67.

Beggs, J.M., and K.L. Dean: 2007, 'Legislated Ethics or Ethics Education? Faculty Views in the Post-Enron Era' Journal of Business Ethics 71, 15-37.

Bodkin , C.D., and T.H. Stevenson: 2007, 'University Students' Perceptions Regarding Ethical Marketing Practices: Affecting Change Through Instructional Techniques’ Journal of Business Ethics 72, 207-228.

Boyce, G.: 2006, 'The social relevance of ethics education in a global(ising) era: From individual dilemma to systemic crises’ Critical Perspectives on Accounting (article in press).

Brinkmann, J., and R.R. Sims: 2001, 'Stakeholder Sensitive Business Ethics Teaching’ Teaching Business Ethics 5(2), 171-193.

Cavanaugh, G. F., \& Frizsche, D. J. (1985). "Using Vignettes in Business Ethics Research”. In Research in Corporate Social Performance and Policy, 279-293.

Cree, M., \& Baring, G. (1991). “Desperately seeking ethics”. Australian Accountant, May. p21-22.

Daly, M.E.: (1997). 'Alternative methods for the Teaching of Ethics' Journal of Pharmacy Teaching 6 (1/2), 77-86. 
Douglas, P. C., Davidson, R. A., \& Schwartz, B. N. (2001). "The effect of organizational culture and ethical orientation on accountants' ethical judgements”. Journal of Business Ethics, 34(2), 101-121.

Gardner, H: 2007, 'The Ethical Mind’ Harvard Business Review, March, 51-56.

Fleischman G.M. Valentine S. and Finn D: 2007, 'Equitable Reason and Ethical Belief'. Behavioral Research in Accounting. 19, 107-133.

Geary, W.T., and R.R. Sims: 1994, 'Can ethics be learned?' Accounting Education 3(1) 3-18.

Gunz, S., and J. McCutcheon: 1998, 'Are Academics Committed to Accounting Ethics Education?’ Journal of Business Ethics 17(11), 1145-1154.

Hanson, K.O.: 1987, 'What good are ethics courses?' Across the Board , September, $10-11$.

Haswell, S., \& Jubb, P. (1995). “Unethical tendencies”. Charter, 66(3), 102-103.

Hiltebeitel, K.M., and Jones, S.K.: 1991, 'Initial Evidence on the Impact of Integrating Ethics into Accounting Education’ 6(2) Issues in Accounting Education 262-276.

International Federation of Accountants (IFAC, 2006) www.ifac.org. 
Kohlberg, L.:1969, 'Stage and Sequence: The Cognitive Development Approach to Socialization', in D.A. Goslin (Ed.), Handbook of Socialization Theory and Research (Rand McNally, Chicago), 347-480.

Kohlberg, L.: 1981, The Meaning and Measurement of Moral Development, Clark University Press, Worcester, MA.

LaGrone, R.M., R.E. Welton, and J.R. Davis: 1996, 'Are the Effects of Accounting Ethics Interventions Transitory or Persistent?' Journal of Accounting Education 14(3), 259-276.

Langenderfer, H.Q., and J.W. Rockness: 1989, 'Integrating Ethics into the Accounting Curriculum: Issues, Problems, and Solution' Issues in Accounting Education 4(1), 58-69.

Leung, P., and B.J.Cooper: 1994, 'Ethics in accountancy: a classroom experience' Accounting Education 3(1), 19-33.

Loeb, S.E.:1988, ‘Teaching Students Accounting Ethics: Some Crucial Issues’ Issues in Accounting Education 3, 316-329.

Loeb, S.E.: 1991, 'The Evaluation of “Outcomes” of Accounting Ethics Education' Journal of Business Ethics 10(2), 77-84. 
Loeb, S. E.: 1998, ‘A Separate Course in Accounting Ethics: An Example’ Advances in Accounting Education 1, 235-250.

Low, M., H. Davey, and K. Hooper: 2006, 'Accounting scandals, ethical dilemmas and educational challenges' Critical perspectives on Accounting, (article in press).

McDonald G.M., and G.D. Donleavy: 1995, 'Objections to the Teaching of Ethics' Journal of Business Ethics 14(10), 839-854.

McNair, F., and E.E. Milam: 1993, 'Ethics in Accounting Education: What is really being done?' Journal of Business Ethics 12, 797-809.

Madison, R.L., and J.J. Schmidt: 2006, 'Survey of Time Devoted to Ethics in Accountancy Programs in North American Colleges and Universities' Issues in Accounting Education 21(2), 99-109.

Mastracchio Jnr., N.J.: 2005, 'Teaching CPAs About Serving the Public Interest' The CPA Journal, January, 6-8.

Michael, M.L.: 2006, ‘Business Ethics: The Law of Rules’ Business Ethics Quarterly 16(4), 475-504.

Mintz, S.M.: 1995, 'Virtue Ethics and Accounting Education’ Issues in Accounting Education 10(2), 247-267. 
O'Leary, C., \& Cotter, D. (2000). “The ethics of final year accountancy students: an international comparison”. Managerial Auditing Journal, 15(3), 108-114.

O'Leary, C., \& Radich, R. (2001). “An Analysis of Australian Final Year Accountancy Students' Ethical Attitudes”. Teaching Business Ethics, 5(3), 235-249.

Patterson, D. M. (2001). Causal effects of regulatory, organizational and personal factors on ethical sensitivity. Journal of Business Ethics, 30(2), 123-159.

Peppas, S.C., and B.A. Diskin: 2001, 'College Courses in Ethics: Do They Really Make a Difference?' The International Journal of Educational Management 15(6/7), 347-354.

Piper, T.R., M.C. Gentile, and S.D. Parks: 1993, Can Ethics Be Taught? Harvard Business School Press.

Ponemon, L.: 1993, 'Can ethics be taught in accounting?' Journal of Accounting Education 11, 185-209.

Reckers, P.M.J.: 2006, 'Perspectives on the proposal for a generally accepted accounting curriculum: A wake-up call for academics' Issues in Accounting Education 21(1), 31-43.

Rest, J.: 1986, Moral development: advances in research theory, New York: Praeger. 
Rest, J.: 1990, DIT Manual, University of Minneapolis Press.

Richards, C.: 1999, 'The Transient Effects of Limited Ethics Training' Journal of Education for Business 74(6), 332-334.

Stewart, I.: 1997, ‘Teaching accounting ethics: The power of narrative’ Accounting Education 2(2), 173-184.

Swanson, D.L.: 2005, 'Business Ethics Education at Bay: Addressing a Crisis of Legitimacy’ Issues in Accounting Education 20(3), 247-253.

Thomas, C W.: 2004, 'An Inventory of Support Materials for Teaching Ethics in the Post-Enron Era’ Issues in Accounting Education 19(1), 27-52.

Thorne, L.: 1998, 'The role of virtue in auditors' ethical decision making: an integration of cognitive-development and virtue-ethics perspectives' Research in Accounting Ethics 4, 291-308.

Waddock, S.: 2005, 'Hollow Men and Women at the Helm...Hollow Accounting Ethics?' Issues in Accounting Education 20(2), 145-150.

Williams, P.F.: 2002, 'Accounting involves ethics, not just technical issues’ Strategic Finance, September, 28-64. 